\title{
A linguagem na atividade de trabalho do docente psicólogo: cenografia e ethos discursivo em um relato de experiência na revista Psicologia em Foco
}

\author{
Language in the psychologist teaching work activity: scenography and discursive ethos in \\ an experience report in the magazine Psicologia em Foco
}

El lenguaje en la actividad de trabajo docente psicólogo: escenografía y ethos discursivo en un informe de experiencia en la revista Psicologia em Foco

\section{Keila de Quadros Schermack ${ }^{\mathrm{i}}$ Ernani Cesar de Freitas ${ }^{\text {ii }}$}

\begin{abstract}
Resumo: Este estudo tem por objetivo analisar as práticas de linguagem no e sobre o trabalho, a cenografia e o ethos discursivo como a construção da imagem de si no discurso do docente psicólogo. O marco teórico se situa sobre as contribuições referentes à abordagem ergológica (SCHWARTZ; DURRIVE, 2010; TRINQUET, 2010; NOUROUDINE, 2002; SOUZA-E-SILVA, FAÏTA, 2002) em interface com a semântica global, de base enunciativo-discursiva (MAINGUENEAU, 1997, 2008a, 2008b, 2008c, 2008d, 2015). A pesquisa é aplicada, descritiva, com procedimentos bibliográfico e documental, numa abordagem qualitativa. Os corpora de pesquisa constituem-se de três excertos de um relato de experiência publicado na revista Psicologia em Foco; Código de Ética Profissional do Psicólogo (2005): o inciso II dos Principios Fundamentais e o Art. $1^{\circ}$ (parágrafo c) Das responsabilidades do Psicólogo. Na construção da cenografia, a imagem de si refletida no relato de experiência revela o ethos discursivo de um profissional responsável, educador, cumpridor de normas, preocupado com o bem estar dos indivíduos, que faz a gestão de si na atividade em prol dos sujeitos envolvidos no trabalho.
\end{abstract}

Abstract: This study aims to analyze language practices in and about work, scenography and discursive ethos as the construction of the image of the self in the speech of the psychologist teacher. The theoretical framework is based on the contributions related to the ergological approach (SCHWARTZ; DURRIVE, 2010; TRINQUET, 2010; NOUROUDINE, 2002; SOUZA-E-SILVA, FAÏTA, 2002) in interface with the global semantics, with an enunciative-discursive basis ( MAINGUENEAU, 1997, 2008a, 2008b, 2008c, 2008d, 2015). The research is applied, descriptive, with bibliographic and documentary procedures, in a qualitative approach. The research corporations consist of three excerpts from an experience report published in the magazine Psicologia em Foco; Psychologist's Professional Code of Ethics (2005): item II of the Fundamental Principles and Art. 1 (paragraph c) Psychologist's responsibilities. In the construction of the scenography, the image of oneself reflected in the experience report reveals the discursive ethos of a responsible professional, educator, norm-abiding, concerned with the well-being of individuals, who manages himself in the activity for the benefit of the subjects involved at work.

Resumen: Este estudio tiene como objetivo analizar las prácticas del lenguaje en y sobre el trabajo, la escenografía y el espíritu discursivo como la construcción de la imagen del yo en el discurso del maestro psicólogo. El marco teórico se basa en las contribuciones relacionadas con el enfoque ergológico (SCHWARTZ; DURRIVE, 2010; TRINQUET, 2010; NOUROUDINE, 2002; SOUZAE-SILVA, FAÏTA, 2002) en interfaz con la semántica global, con una base enunciativa-discursiva (MAINGUENEAU, 1997, 2008a, 2008b, 2008c, 2008d, 2015). La investigación se aplica, descriptiva, con procedimientos bibliográficos y documentales, en un enfoque cualitativo. Las corporaciones de investigación consisten en tres extractos de un informe de experiencia publicado en la revista Psicologia em Foco; Código de Ética Profesional del Psicólogo (2005): ítem II de los Principios Fundamentales y Art. 1 (párrafo c) Responsabilidades del psicólogo. En la construcción de la escenografía, la imagen de uno mismo reflejada en el informe de experiencia revela el carácter discursivo de un profesional responsable, educador, respetuoso de las normas, preocupado por el 
bienestar de las personas, que se maneja en la actividad en beneficio de los sujetos involucrados en el trabajo.

Palavras-chave: Linguagem e Trabalho; Relato de experiência; Cenografia e ethos discursivo.

Keywords: Language and work; Experience report; Scenography and discursive ethos.

Palabras claves: Lengua y trabajo; Informe de experiencia; Escenografía y ethos discursivo.

\section{INTRODUÇÃO}

Este estudo respalda-se em uma abordagem teórico-metodológica de cunho enunciativo que interessa-se pelas pesquisas desenvolvidas na interface entre Linguagem $e$ Trabalho. A concepção de trabalho abordada nesta pesquisa, considera o sujeito como ser atuante na atividade laboral. $\mathrm{O}$ aporte teórico-conceitual sobre a semântica global cenografia e ethos discursivo (MAINGUENEAU, 2008a, 2008b) - é fundamental para compreender o sujeito em situações de trabalho, sua formação como ser social, devido à construção de uma imagem de si que se revela no discurso, no seu contexto laboral. O sujeito está envolvido em toda sua singularidade na atividade, pois trabalhar é fazer escolhas que vão além das normas presentes nas instituições e nos códigos de ética.

A escolha do tema Linguagem e trabalho justifica-se pela necessidade de aprofundamento dos estudos e pesquisas sobre a atividade do docente/psicólogo em instituições de ensino e de acolhimento institucional (de crianças e adolescentes), visto que a formação acadêmica do psicólogo habilita o profissional a exercer suas atividades em diferentes áreas de atuação e espaços institucionais. Assim, juntamente com outras abordagens voltadas para esse campo da interface Linguagem e trabalho, pretendemos contribuir com a discussão e reflexão acerca do trabalho do docente/psicólogo.

A questão norteadora de pesquisa que conduz o desenvolvimento deste estudo é a seguinte: os docentes psicólogos encontram, no trabalho, na atividade docente e nas instituições de acolhimento complexos desafios que envolvem o constante diálogo com diferentes sujeitos, mobilizam saberes constituídos e investidos, renormalizam a atividade fazendo a gestão e "uso de si por si e pelos outros" mediante cenografias instituídas, das quais emergem o ethos discursivo como imagem de si.

O objetivo deste estudo visa compreender práticas de linguagem no e sobre o trabalho, cujos discursos envolvem a prescrição e a atividade do docente psicólogo com base na(s) cenografia(s) de onde emerge o ethos discursivo na atividade, em situações de trabalho. O corpus de pesquisa contempla cenas enunciativas e cenografias que se verificam nos excertos extraídos de um relato de experiência na revista Psicologia em Foco, editada pelo 
Curso de Psicologia da Universidade Regional Integrada do Alto Uruguai e das Missões (URI - Câmpus Frederico Westphalen-RS/Brasil).

No que diz respeito à base teórica, conferimos especial destaque a contribuições referentes à abordagem ergológica (SCHWARTZ; DURRIVE, 2010; TRINQUET, 2010; NOUROUDINE, 2002) em interface com a semântica global, de base enunciativo-discursiva (MAINGUENEAU, 2008a, 2008b).

Este estudo desenvolve-se mediante preceitos da pesquisa exploratória, bibliográfica e documental com abordagem qualitativa na análise do objeto. Os corpora selecionados para pesquisa constituem-se de três excertos de um relato de experiência extraídos da revista Psicologia em Foco (2014, vol. 6, n. 7). Também analisaremos o Código de Ética profissional do Psicólogo (2005): o inciso II dos Princípios Fundamentais e o Art. $1^{\circ}$ (parágrafo c) Das responsabilidades do Psicólogo.

Estruturalmente, o texto está assim organizado: primeiramente, detalham-se breves conceitos teóricos articulados acerca da Ergologia, da cenografia e do ethos discursivo. $\mathrm{Na}$ sequência, consta a metodologia empregada. Posteriormente, apresenta-se uma breve análise dos corpora. Por último, constam as considerações finais e as referências.

\section{ERGOLOGIA, CENOGRAFIA E ETHOS: AS MANEIRAS DE DIZER E AS IMAGENS DE SI}

A Ergologia é a aprendizagem permanente dos debates de normas e de valores que renovam indefinidamente a atividade: é o "desconforto intelectual”. A perspectiva ergológica está sempre em negociação de normas, debatendo valores. Trata-se de normas anteriores à própria atividade: a atividade negocia essas normas em função daquilo que são as suas próprias. Não podemos falar de trabalho sem considerar que o sujeito se faz presente no interior da atividade através das suas escolhas. Aquele que julga a situação de trabalho do docente psicólogo sem aprender com a própria pessoa como ela vivencia essa situação, fala no lugar do outro.

A linguagem é o resultado de uma atividade humana, da qual faz parte o enunciador e o coenunciador (eu/tu) que agem discursivamente no mundo, situando-se sóciohistoricamente. Consequentemente, a singularidade e a subjetividade dos sujeitos estão imbricadas na atividade de trabalho. O trabalho é sempre singularização ou ressingularização, que envolve ações subjetivas e intersubjetivas porque não agimos de forma individual. Não trabalhamos sozinhos. 
Os sujeitos expressam suas singularidades nas escolhas linguístico-discursivas em situações de trabalho, considerando seus saberes instituídos e investidos mobilizados na atividade, ou seja, na própria tarefa executada.

A perspectiva do ato enunciativo perpassa a reflexão sobre o estatuto do enunciador e o destinatário, a dêixis enunciativa e o modo de enunciação ${ }^{1}$. Quando fala sobre o trabalho, o enunciador (eu) realiza escolhas linguísticas no aqui a agora. Essa enunciação acontece numa determinada cena enunciativa ${ }^{2}$, da qual fazem parte os sujeitos envolvidos na atividade de trabalho. A partir da cenografia instaurada discursivamente, revela-se quem é o enunciador, que se constitui no ethos discursivo, evidenciando uma imagem de si.

$\mathrm{Na}$ atividade laboral há um uso de si por si e pelos outros que ultrapassa a pura e simples "execução" das tarefas pelo trabalhador. O sujeito se faz presente no interior do trabalho, pois dedicar-se à atividade de trabalho é colocar a prova os próprios limites, as próprias capacidades, isto é, correr riscos. Como o trabalho não é realizado de antemão, o sujeito vai se encontrar em situação de prova. "De prova de existência enquanto 'si'no trabalho" (SCHWARTZ; DURRIVE, 2010, p. 191).

O uso de si remete ao uso do próprio corpo do sujeito no ato do trabalho, uso de sua inteligência, sua história, seus valores, sua sensibilidade, seus gostos. Se trabalhar implica a aplicação de um protocolo, pertencente ao trabalho prescrito, ao mesmo tempo ele sempre será aplicado de maneira singular, diferente daquela de um colega de trabalho e mesmo diferente de um momento a outro (trabalho real).

Feitas essas considerações acerca da ergologia, cenografia e ethos discursivo, apresentamos os procedimentos metodológicos que nortearam essa pesquisa.

\section{Procedimentos metodológicos}

A metodologia na qual se ampara esse estudo tem como base a obra Metodologia do trabalho cientifico, de Prodanov e Freitas (2013). A pesquisa classifica-se como aplicada, qualitativa, descritiva, bibliográfica e documental. Os corpora selecionados para pesquisa constituem-se de três excertos de um relato de experiência extraídos da revista Psicologia em Foco, uma publicação de periodicidade semestral destinada à comunidade acadêmica.

\footnotetext{
${ }^{1} \mathrm{O}$ estatuto do enunciador e do destinatário, a dêixis enunciativa e o modo de enunciação fazem parte dos sete planos discursivos da semântica global, utilizados por Maingueneau (2008a).

${ }^{2}$ Maingueneau (2008b) define que a cena de enunciação se compõe de três cenas: "cena englobante", "cena genérica" e "cenografia". A cena englobante equivale ao tipo de discurso: publicitário, administrativo, filosófico, etc. A cena genérica equivale aos gêneros do discurso que são mobilizados para influenciar o coenunciador. A cenografia é a cena de fala que o discurso pressupõe para ser enunciado, é o elemento textual com que o coenunciador entra em contato num primeiro momento.
} 
Também analisaremos o Código de Ética profissional do Psicólogo (2005): o inciso II dos Princípios Fundamentais e o Art. $1^{\circ}$ (parágrafo c) Das responsabilidades do Psicólogo. Por meio da interface entre as respectivas áreas do conhecimento, estabeleceremos o seguinte percurso teórico-metodológico:

- Na ergologia (SCHWARTZ; DURRIVE, 2010): o trabalho como atividade envolvendo as normas antecedentes e renormalizações; o debate de valores ligado ao debate de normas (as impostas e as instituídas na atividade); os saberes (constituídos e investidos) e o agir em competência; trabalho e uso de si; na abordagem enunciativo-discursiva da semântica global (MAINGUENEAU, 2008a, 2008b): estatuto do enunciador e do destinatário, dêixis enunciativa e modo de enunciação para descrever, a cenografia enunciativa e o ethos como imagem de si.

Conforme os procedimentos metodológicos aqui descritos, apresentaremos um esboço da análise dos corpora.

\section{ANÁlise E ALGUNS RESULTADOS}

Nesta seção, apresentaremos uma breve análise dos corpora com alguns resultados parciais.

Quadro 1 - Excertos 1

Princípios Fundamentais: Inciso II.

II. O psicólogo trabalhará visando promover a saúde e a qualidade de vida das pessoas e das coletividades e contribuirá para a eliminação de quaisquer formas de negligência, discriminação, exploração, violência, crueldade e opressão.

Das responsabilidades do Psicólogo: Art. $1^{\circ}$ (parágrafo C)

c) Prestar serviços psicológicos de qualidade, em condições de trabalho dignas e apropriadas à natureza desses serviços, utilizando princípios, conhecimentos e técnicas reconhecidamente fundamentados na ciência psicológica, na ética e na legislação profissional;

Ao ingressar na casa, por exemplo, com o suposto objetivo de atender ao preconizado no Estatuto da Criança e do Adolescente (BRASIL, 1990) em seu artigo 94, e demonstrando evidente equívoco na interpretação deste (que no inciso XVII refere, entre as obrigações das entidades que executam programas de internação de adolescentes, o fornecimento de depósito de pertences), as crianças eram instruídas a guardar todos seus objetos pessoais e roupas, que eram acumuladas em um "armário de pertences" e devolvidas ao final do período de abrigagem. Tal medida, evidentemente, privava a criança do contato com alguns objetos que poderiam auxiliá-la a suportar a separação de seus familiares, e foi posteriormente, depois de repetidas discussões neste sentido, abolida. 
De acordo com Schwartz e Durrive (2010), as normas organizam o trabalho e são estabelecidas com o objetivo de prescrever, antecipadamente, as atividades que o trabalhador deve executar. Os excertos do relato de experiência e do Código de Ética do Psicólogo revelam que para realizar a gestão de si na atividade do docente/psicólogo, há uma distância entre o trabalho prescrito e o trabalho real. O profissional se vê em meio a normas e a constante tensão em renormalizá-las. Podemos observar isso no seguinte trecho, atribuindo destaque a palavra "abolida" e a frase "depois de repetidas discussões": "Tal medida, evidentemente, privava a criança do contato com alguns objetos que poderiam auxiliá-la a suportar a separação de seus familiares, e foi posteriormente, depois de repetidas discussões neste sentido, abolida”. As renormalizações recriam continuamente algo novo.

Com o objetivo de melhor atender às necessidades pessoais (subjetivas) das crianças e adolescentes que recebem atendimento na instituição, o docente/psicólogo se depara com a indispensabilidade de observar e conhecer as diferentes regras que permeavam o serviço a fim de reavaliá-las. Nesse contexto, Schwartz (2014, p. 261) afirma que as renormalizações obrigam os sujeitos a escolher e a se escolher, na qualidade de seres às voltas com um mundo de valores.

Tudo isso remete a gestão da distância entre o trabalho prescrito e o real que cria a subjetividade do/no trabalho. Nas palavras de Trinquet (2010, p. 98), "É nesse momento que se expressa a personalidade, a individualidade, a história sempre singular, tanto individual quanto coletiva daqueles que participam em tempo real". São todos os dramas resultantes da atividade laboriosa, na ergologia, que são nomeados de dramáticas dos usos de si.

Percebemos que as prescrições/regulamentações das normas, que se estabelecem sobre o trabalho docente/psicólogo são de diversas naturezas, pois além do Código de Ética que regulamenta a profissão, há o objetivo - por parte desse profissional - de atender ao preconizado no Estatuto da Criança e do Adolescente (ECA), já que o acolhimento institucional de crianças e adolescentes faz parte da atividade.

Assim, todas as normas implicam na dualidade denominada "dramáticas" por Schwartz e Durrive (2010, p. 194): "fui levado a propor a ideia de que toda atividade - todo trabalho - é sempre uso. Uso de si, mas com essa dualidade às vezes simples e ao mesmo tempo muito complicada, que é uso de si "por si'e "pelos outros"”. Aqui reside uma dupla "dramática da atividade", no sentido de que há um profissional que faz uso de si "por si" e "pelos outros" tanto na função de educador quanto na atividade de psicólogo.

Observemos outros excertos do relato de experiência: 
Quadro 2 - Excertos 2

Também era possível perceber a dificuldade da instituição de respeitar a subjetividade da criança na forma como eram realizadas comemorações de aniversário, que a despeito do orçamento considerável da instituição e do pequeno número de crianças acolhidas, festejava-se coletivamente, com datas estipuladas para isto em cada mês. Este modo de funcionamento também foi revisto posteriormente, ressaltando-se a importância de que cada criança pudesse ganhar seu presente de aniversário e comemorá-lo ao menos com o bolo caseiro preparado para o lanche, no dia correto.

A despeito do desconforto que a constatação destas questões provocava na autora, um espaço importante de discussão sobre as mesmas era oferecido pelas reuniões semanais de equipe, da qual participavam gerência, equipe técnica e um representante dos educadores. Nestes momentos, além da discussão destas normas, era possível também socializar aspectos importantes sobre o trabalho com as crianças, discutir formas de intervenção e estabelecer uma compreensão conjunta sobre suas necessidades e características, o que permitia a elaboração de um projeto de atendimento e a discussão sobre a parte neste que cabia a cada membro da equipe.

Nos excertos destacados no relato de experiência, o "eu" enuncia na instância de enunciação, dirigindo-se a um "tu" que são os leitores da revista Psicologia em Foco. Nas palavras de Maingueneau (2008a, p. 87), “cada discurso define o estatuto que o enunciador deve se atribuir e o que deve atribuir a seu destinatário para legitimar seu dizer”. O enunciador relata e compartilha com o destinatário as dificuldades encontradas na atividade docente/psicólogo em uma instituição de acolhimento de crianças e adolescentes, enfatizando o fazer psicológico neste contexto. Este enunciador se considera integrado a uma "ordem", pois enuncia enquanto membro de instituições (educacional e acolhimento institucional).

O "eu" evidencia uma cenografia associada à imagem de um profissional preocupado em cumprir as normas da instituição; e busca respeitar rigorosamente o preconizado no Código de Ética profissional do Psicólogo (inciso II dos Princípios Fundamentais e o Art. $1^{\circ}$ - parágrafo c: Das responsabilidades do Psicólogo) e no Estatuto da Criança e do Adolescente (1990), conforme verificamos nos trechos: "Nestes momentos, além da discussão destas normas, era possivel também socializar aspectos importantes sobre o trabalho com as crianças, discutir formas de intervenção e estabelecer uma compreensão conjunta sobre suas necessidades e características, o que permitia a elaboração de um projeto de atendimento e a discussão sobre a parte neste que cabia a cada membro da equipe”.

A maneira de dizer do enunciador revela, na cenografia instaurada, o respeito à subjetividade dos indivíduos acolhidos na instituição e a preocupação com o 
aperfeiçoamento profissional com vistas a melhor atender às necessidades das crianças e adolescentes, como é possível perceber nas afirmações: "Também era possivel perceber a dificuldade da instituição de respeitar a subjetividade da criança na forma como eram realizadas comemorações de aniversário...".

Nos excertos discursivos, o "eu" busca distanciar-se do próprio dizer fazendo uso da terceira pessoa do discurso (ele), conforme podemos ver no seguinte trecho: " $A$ despeito do desconforto que a constatação destas questões provocava na autora, um espaço importante de discussão sobre as mesmas era oferecido pelas reuniões semanais de equipe...". Mesmo que o "eu" não se faça presente na materialidade discursiva, sabemos que o ato de enunciação supõe a instauração de uma dêixis enunciativa $E u-T u$ - Aqui - Agora. "Todo ato de tomar a palavra implica a construção de uma imagem de si" (AMOSSY, 2013, p. 09). Como se trata de um relato de experiência, o "eu" subjacente nos enunciados também revela a subjetividade do sujeito, que ao se apropriar de suas funções na instituição de acolhimento, constrói cenografias que refletem e refratam a imagem de si (professor/psicólogo) e do outro (leitores da revista e /ou profissionais envolvidos na atividade; as crianças e os adolescentes).

Desse modo, a materialidade discursiva revela que o "eu" enuncia para o "tu" e instaura os acontecimentos no presente do seu dizer. O trecho "reuniões semanais de equipe" revela que a enunciação instaura-se sempre no tempo presente da tomada da palavra pelo locutor. Essa instância organizada no tempo e no espaço revela a dêixis enunciativa. "Essa dêixis, em sua dupla modalidade espacial e temporal, define de fato uma instância de enunciação legítima, delimita a cena e a cronologia...” (MAINGUENEAU, 2008a, p. 89), construída pelo discurso para autorizar e legitimar a enunciação.

A cenografia e o ethos como imagem de si refletidos no relato de experiência revelam os ethos discursivos: profissional responsável, educador, cumpridor de normas, preocupado com o bem estar dos indivíduos, atualizado, autônomo na tomada de decisões, que faz a gestão de si na atividade, em prol dos sujeitos envolvidos no trabalho.

\section{CONSIDERAÇÕES FINAIS}

Este estudo, de cunho interdisciplinar, que respaldou-se em uma abordagem teórico-metodológica, na perspectiva enunciativa, mediante a interface Linguagem e trabalho, teve como principais autores Schwartz e Durrive (2010) e Trinquet (2010); em relação a linguagem no e sobre o trabalho, Nouroudine (2002). No que diz respeito aos pressupostos enunciativo-discursivos, utilizamos Maingueneau (2008a, 2008b) e alguns de seus estudiosos. 
A escolha do tema foi Linguagem e trabalho, abordando as práticas de linguagem no e sobre o trabalho, e teve como delimitação a análise de discursos de um relato de experiência (redigido por um docente/psicólogo) publicado na revista Psicologia em Foco.

A questão norteadora de pesquisa foi atendida à medida que verificamos pistas linguístico-discursivas confirmadoras de que os docentes/psicólogos encontram, no trabalho em instituições de acolhimento, complexos desafios e peculiaridades que envolve o constante diálogo com diferentes sujeitos (colegas de trabalho, crianças e adolescentes), mobilizam saberes a partir dos próprios estudos e das prescrições impostas pelo Código de Ética que rege a profissão.

A partir do prescrito e da sua subjetividade, o trabalhador renormaliza e singulariza no sentido de desenvolver sua atividade, fazendo a gestão e "uso de si por si e pelos outros" mediante cenografias instituídas, das quais emergem o ethos discursivo desse profissional diante das cenas enunciativas que se verificam nos excertos extraídos do um relato de experiência.

Dessa forma, o objetivo central desta pesquisa foi alcançado, pois visou compreender práticas de linguagem no e sobre o trabalho, cujos discursos envolvem a prescrição e a atividade do docente psicólogo com base na(s) cenografia(s) de onde emerge o ethos discursivo na atividade, em situações de trabalho.

Constatamos, nesse sentido, que as prescrições existentes na atividade do docente/psicólogo provêm das normas estabelecidas pela instituição, normas estas que muitas vezes entram em conflito com o preconizado no Código de Ética do Psicólogo (2005) e no Estatuto da Criança e do Adolescente (1990). Porém, o profissional não age passivamente, na medida que faz algumas renormalizações do prescrito e se apropria de novos saberes, confrontando-se com as dramáticas de uso de si por si e pelos outros na atividade laboral. As renormalizações recriaram novas formas de intervenção com os sujeitos (crianças e adolescentes) na instituição de acolhimento.

A respeito da perspectiva ergológica e dos pressupostos da cenografia e do ethos discursivo, depreendemos por meio das marcas linguístico-discursivas, como se constrói a cenografia e o ethos no discurso do docente/psicólogo (materializado no relato de experiência), o que nos possibilitou a compreensão das relações de trabalho deste profissional com os sujeitos envolvidos na atividade.

Acreditamos que a contribuição desse estudo situa-se na possibilidade em poder auxiliar nos estudos interdisciplinares que envolvem a temática Linguagem e trabalho. Além 
disso, vislumbramos contribuir no sentido de mostrar um olhar enunciativo-discursivo para a questão da atividade de trabalho do docente/psicólogo.

\section{REFERÊNCIAS}

AMOSSY, Ruth. Da noção retórica de ethos à análise do discurso. In: . Imagens de si no discurso: a construção do ethos. 2. ed. São Paulo: Contexto, 2013. p. 9-27.

BRASIL. Estatuto da criança e do adolescente. São Paulo: Cortez, 1990.

MAINGUENEAU, Dominique. Uma semântica global. In: . Gênese dos discursos. Tradução Sírio Possenti. São Paulo: Parábola Editorial, 2008a. p. 75-97. . Ethos, cenografia, incorporação. In: AMOSSY, Ruth (Org.). Imagens de si no discurso: a construção do ethos. 1. ed. São Paulo: Contexto, 2008b. p. 68-92.

PRODANOV, Cleber Cristiano; FREITAS, Ernani Cesar de; Metodologia do trabalho científico: métodos e técnicas da pesquisa e do trabalho acadêmico. Novo Hamburgo: Feevale, 2013.

NOUROUDINE, Abdallah. A linguagem: dispositivo revelador da complexidade do trabalho. In: SOUZA-e-SILVA, Maria Cecília Pérez; FAÏTA, Daniel. (orgs.). Linguagem e trabalho: construção de objetos de análise no Brasil e na França. São Paulo: Cortez, 2002, p. $17-30$.

PSICOLOGIA, XIII PLENÁRIO DO CONSELHO FEDERAL DE. Código de Ética Profissional do Psicólogo. Brasília: CFP, 2005.

SCHWARTZ, Yves; DURRIVE, Louis. Trabalho e ergologia: conversas sobre a atividade humana. 2. ed. Niterói: Ed UFF, 2010.

SCHWARTZ, Yves. Motivações do conceito de corpo-si: corpo si, atividade, experiência. Letras de hoje, Porto Alegre, v. 49, n. 3, p. 259-274, jul.-set. 2014.

STAHLSCHMIDT, Ana Paula Melchiors. Reflexões sobre a práxis do psicólogo em equipamentos de acolhimento institucional: relato de uma experiência. Psicologia em Foco, Frederico Westphalen, RS, v.6, n.7, p. 40-50, jul. 2014.

TRINQUET, Pierre. Trabalho e educação: o método ergológico. Revista HISTEDBR Online, Campinas, n. esp., p. 93-112, ago.2010.

\footnotetext{
${ }^{\text {i }}$ Doutoranda em Letras, Programa de Pós-Graduação em Letras, Universidade de Passo Fundo (UPF). Passo Fundo- RS. E-mail: keila schermack@yahoo.com.br.

iiDoutor em Letras (PUCRS), com pós-doutorado em Linguística Aplicada e Estudos da Linguagem (PUCSP/LAEL); professor do Mestrado e Doutorado em Letras, Universidade de Passo Fundo (UPF/RS); professor do Mestrado em Processos e Manifestações Culturais, Universidade Feevale (Novo Hamburgo/RS). E-mail: ecesar@upf.br.
} 